\title{
Nanostructured SiGe:Sb solid solutions with improved thermoelectric figure of merit
}

\section{Mikhail Vladimirovich Dorokhin ( $\nabla$ dorokhin@nifti.unn.ru )}

Nacional'nyj issledovatel'skij Nizegorodskij gosudarstvennyj universitet imeni N I Lobacevskogo https://orcid.org/0000-0001-5238-0090

\section{Polina Borisovna Demina}

Nacional'nyj issledovatel'skij Nizegorodskij gosudarstvennyj universitet imeni N I Lobacevskogo Irina Viktorovna Erofeeva

Nacional'nyj issledovatel'skij Nizegorodskij gosudarstvennyj universitet imeni N I Lobacevskogo Yuri Mikhailovich Kuznetsov

Nacional'nyj issledovatel'skij Nizegorodskij gosudarstvennyj universitet imeni N I Lobacevskogo Anton Vladimirovich Zdoroveyshchev

Nacional'nyj issledovatel'skij Nizegorodskij gosudarstvennyj universitet imeni N I Lobacevskogo Maksim Sergeevich Boldin

Nacional'nyj issledovatel'skij Nizegorodskij gosudarstvennyj universitet imeni N I Lobacevskogo Evgeniy Andreevich Lantsev

Nacional'nyj issledovatel'skij Nizegorodskij gosudarstvennyj universitet imeni N I Lobacevskogo

\section{Aleksandr Andreevich Popov}

Nacional'nyj issledovatel'skij Nizegorodskij gosudarstvennyj universitet imeni N I Lobacevskogo

\section{Elena Afanas'evna Uskova}

Nacional'nyj issledovatel'skij Nizegorodskij gosudarstvennyj universitet imeni N I Lobacevskogo

\section{Vladimir Nikolaevich Trushin}

Nacional'nyj issledovatel'skij Nizegorodskij gosudarstvennyj universitet imeni N I Lobacevskogo

\section{Rapid Communication}

Keywords: thermoelectric energy converters, spark plasma sintering, doping, germanium-silicon, thermoelectric figure of merit

Posted Date: April 29th, 2020

DOl: https://doi.org/10.21203/rs.3.rs-24756/v1

License: (c) (i) This work is licensed under a Creative Commons Attribution 4.0 International License. Read Full License 
Version of Record: A version of this preprint was published at Nanosystems: Physics, Chemistry, Mathematics on December 30th, 2020. See the published version at https://doi.org/10.17586/2220-80542020-11-6-680-684. 


\section{Nanostructured SiGe:Sb solid solutions with improved thermoelectric figure of merit}

M.V. Dorokhin, P.B. Demina, I.V. Erofeeva, Yu.M. Kuznetsov, A.V. Zdoroveyshchev, M.S. Boldin, E.A. Lantsev, A.A. Popov, E.A. Uskova, V.N. Trushin

Lobachevsky State University of Nizhny Novgorod, 603950, Gagarin ave.23, Nizhniy Novgorod, Russia

e-mail: dorokhin@nifti.unn.ru

\section{Abstract}

Thermoelectric $\mathrm{Si}_{0,65} \mathrm{Ge}_{0,35} \mathrm{Sb}_{\delta}$ materials have been fabricated by spark plasma sintering of $\mathrm{Ge}-\mathrm{Si}$ $\mathrm{Sb}$ powder mixture. The electronic properties of $\mathrm{Si}_{0,65} \mathrm{Ge}_{0,35} \mathrm{Sb}_{\delta}$ were found to be dependent on the uniformity of mixing of the components, which in turn is determined by the maximum heating temperature during solid-state sintering. Provided the concentration of donor Sb impurity is optimized the thermoelectric figure of merit for the investigated structures can be as high as 0.628 at the temperature of $490^{\circ} \mathrm{C}$, the latter value is comparable with world-known analogues obtained for $\mathrm{Si}_{1-x} \mathrm{Ge}_{x} \mathrm{P}_{\delta}$.

Keywords: thermoelectric energy converters, spark plasma sintering, doping, germanium-silicon, thermoelectric figure of merit

\section{Introduction}

The $\mathrm{Si}_{1-x} \mathrm{Ge}_{x}$ substitutional solid solution is at a special place among thermoelectric energy converters as the most promising silicon-based material [1-3]. For this material high chemical and mechanical stability at elevated temperatures is an important advantage when concerning the applications in the air atmosphere. Some other advantages of $\mathrm{Si}_{1-x} \mathrm{Ge}_{x}$ are low toxicity and a high degree of development of technological processes for $\mathrm{Ge}$ and $\mathrm{Si}$ [4]. The main characterizing parameter of thermoelectric materials is the dimensionless thermoelectric figure of merit $(Z T)$

$$
Z T=\frac{\alpha^{2} \sigma}{\varkappa} \cdot T,
$$

where $x$ is the thermal conductivity, $\sigma$ is electrical conductivity (sometimes resistivity $\rho$ $=1 / \sigma$ can be used instead) and $\alpha$ is a Seebeck coefficient which can be determined by measuring the thermo-voltage $\left(U_{\mathrm{TE}}\right)$ and a temperature difference $(\Delta T)$ between the "hot" and "cold" edges of the material: $\alpha=U_{\mathrm{TE}} / \Delta T$.
As a rule, the parameters in (1) are not independent within one material: with increasing $\sigma$, the Seebeck coefficient decreases and $x$ increases [5]. Modern technologies such as nanostructuring provide quasi-independent control of thermoelectric coefficients, which allows one to obtain simultaneously low values of $\varkappa$ with high values of $\alpha$ and $\sigma$, and, thus, to increase $Z T$ [2,3,5]

In the present paper we report on the results of investigating $\quad \mathrm{Si}_{0.65} \mathrm{Ge}_{0.35}$ thermoelectric structures fabricated by the technique of spark plasma sintering (SPS) of the mixture of $\mathrm{Si}, \mathrm{Ge}$ and $\mathrm{Sb}$ powders. The SPS technique provides unique possibilities for the formation of nanostructured materials and controlling their parameters [6,7]. Feature of this work is the use of Sb impurities for fabricating the $\mathrm{Si}_{1-x} \mathrm{Ge}_{x}$, with $n$-type conductivity whereas in the majority of the papers As or $\mathrm{P}$ impurities are used. The advantages of antimony in comparison with $\mathrm{P}$ or As [1-6] are lower toxicity, as well as the 
possibility of a new technological option for fabricating the $n$-type material.

Although antimony has limited solubility in Ge and $\mathrm{Si}$ [8], the use of non-equilibrium fabrication techniques such as SPS allows introducing the impurity over the solubility limit and achieving the doping concentrations sufficient for obtaining high values of $Z T$. In this paper the variation of $\mathrm{Sb}$ concentration as well as of the sintering modes has been carried out in order to obtain the increased $Z T$ values. The top value obtained was as high as $Z T=0.628$ at $490{ }^{\circ} \mathrm{C}$ which is comparable with values characteristic for a "classical" phosphorous or boron doped Ge-Si material $[2,6,9]$.

\section{Experimental}

A series of 5 samples of nanostructured $\mathrm{Si}_{0.65} \mathrm{Ge}_{0.35} \mathrm{Sb}_{\delta}$ ( $\left.\delta=0.005-0.009\right)$ was made for this study. The initial powder to be sintered was fabricated by milling the high-purity Ge, Si and Sb bulk pieces with Fritsch Pulverisette 6 ball mill with zirconia grinding media and grinding bowl filled with argon to prevent the oxidation. The milling modes ( 6 hours, 250 RPM) provided the average particle size of $50-500 \mathrm{~nm}$. The composition of the material was set by weighing the $\mathrm{Ge}, \mathrm{Si}$ and $\mathrm{Sb}$ pieces and then converting the weight percent to atomic.

The sintering was carried out using the DR. Sinter Model SPS-625 spark plasma sintering system. The variable parameters were the $\mathrm{Sb}$ concentration (0.5-0.9 at.\%) and a maximal sintering temperature $\left(T_{\mathrm{s}}=1080-1180{ }^{\circ} \mathrm{C}\right)$. The other sintering parameters (pressure of $70 \mathrm{MPa}$, heating rate of $50{ }^{\circ} \mathrm{C} / \mathrm{min}$ ) were kept constant. The sintering temperature was determined by a pyrometer on the outer wall of the mold with sintered powder, with further conversion to the temperature inside the mold [10]. The technological parameters and some measurement results are presented at Table.1.

The sintered ingots of $\mathrm{Si}_{0.65} \mathrm{Ge}_{0.35} \mathrm{Sb}_{\delta}$ were cut into plates on which phase composition studies using X-ray diffraction (XRD) analysis, as well as measurements of thermoelectric coefficients were performed. The Seebeck coefficient was calculated from simultaneous temperature and thermoelectric voltage measurements using chromel-alumel thermocouples [11]. The resistivity was measured by the standard fourprobe method. The thermal conductivity was measured by the stationary heat flux method [12]. The measurements were carried out in the temperature range of $T_{\mathrm{m}}=50-490{ }^{\circ} \mathrm{C}$. The technology for structures fabrication, as well as all measurement techniques, are described in detail in [7,11].

Table 1. Technological parameters of fabricated Si-Ge samples

\begin{tabular}{|c|c|c|}
\hline Sample & $\begin{array}{c}\text { Technological Sb } \\
\text { content }(\delta), \text { at. } \%\end{array}$ & $\begin{array}{c}\text { Sintering temperature } \\
\left(T_{\mathrm{s}}\right),{ }^{\circ} \mathrm{C}\end{array}$ \\
\hline $\mathbf{1}$ & 0.5 & $1080 \pm 10$ \\
\hline $\mathbf{2}$ & 0.5 & $1180 \pm 10$ \\
\hline $\mathbf{3}$ & 0.7 & $1150 \pm 10$ \\
\hline $\mathbf{4}$ & 0.7 & $1180 \pm 10$ \\
\hline $\mathbf{5}$ & 0.9 & $1180 \pm 10$ \\
\hline
\end{tabular}

\section{Results and discussion}

Fig.1 shows X-ray diffraction spectra of the initial powder (1) and samples $(1,3,5)$ formed at various temperatures. The lines corresponding to unmixed $\mathrm{Ge}$ and $\mathrm{Si}$ are present in the diffraction pattern of the initial powder (1).

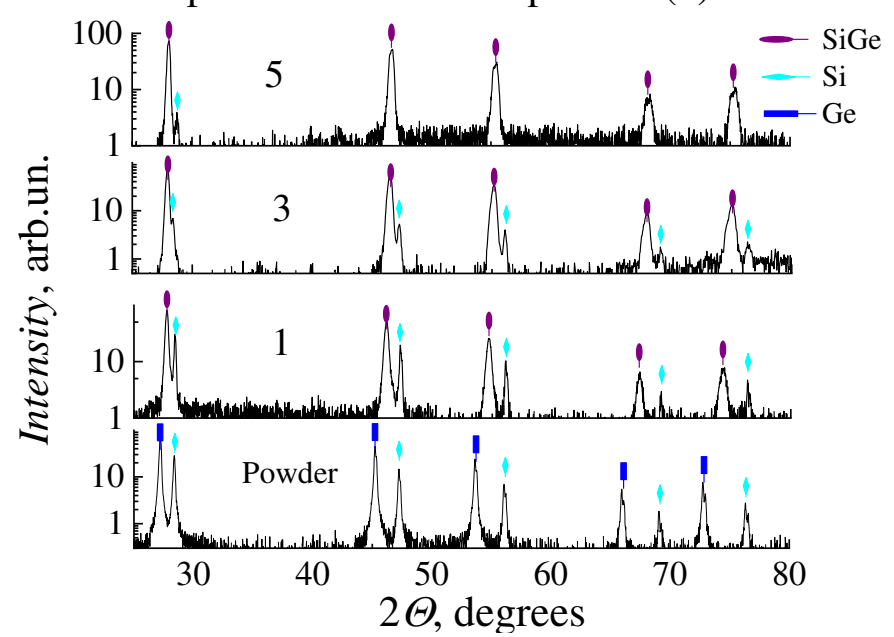

Fig.1. X-ray diffraction pattern for samples 1, 3, and 5 , as well as for the initial powder (Powder). The icons indicate the positions of the peaks for $\mathrm{Si}, \mathrm{Ge}$, and a GeSi solid solution.

Lines associated with $\mathrm{Sb}$ were not resolved due to low concentration. Sintering of a powder at $T_{\mathrm{s}}=1080-1180^{\circ} \mathrm{C}$ leads to the interaction between the components and to the appearance a $\mathrm{Si}_{1-x} \mathrm{Ge}_{x}$ solid solution associated lines at the 
spectra (Fig.1, curves 1,3,5). This is accompanied by vanishing the Ge-related lines from the spectra, whereas Si-related lines are preserved and their intensity monotonically decreases with the increase of $T_{\mathrm{s}}$. The latter is attributed to increase of $\mathrm{Si}$ and $\mathrm{Ge}$ intermixing with the increase of sintering temperature.

Fig.2 shows the temperature dependence of resistivity. All samples were n-type conductivity. For the sample 1 fabricated at the lowest temperature of $T_{\mathrm{s}}=1080^{\circ} \mathrm{C}$, the dependence is a semiconductor type, and the resistivity value is the highest among the investigated structures. The $\rho\left(T_{m}\right)$ dependences for the Samples 2-5 (which were fabricated at the elevated temperatures) are similar: all the curves are peak functions with the maximum at $200-300{ }^{\circ} \mathrm{C}$ and the resistivity values varying slightly in the range of $T_{m}=30-490{ }^{\circ} \mathrm{C}$. In case of same impurity concentration, a lower value of $\rho$ is characteristic for samples sintered at higher temperatures. An increase in impurity concentration in the range of 0.5-0.9 a.\% leads to decrease of $\rho$ which is typical for impurity doping of semiconductors.

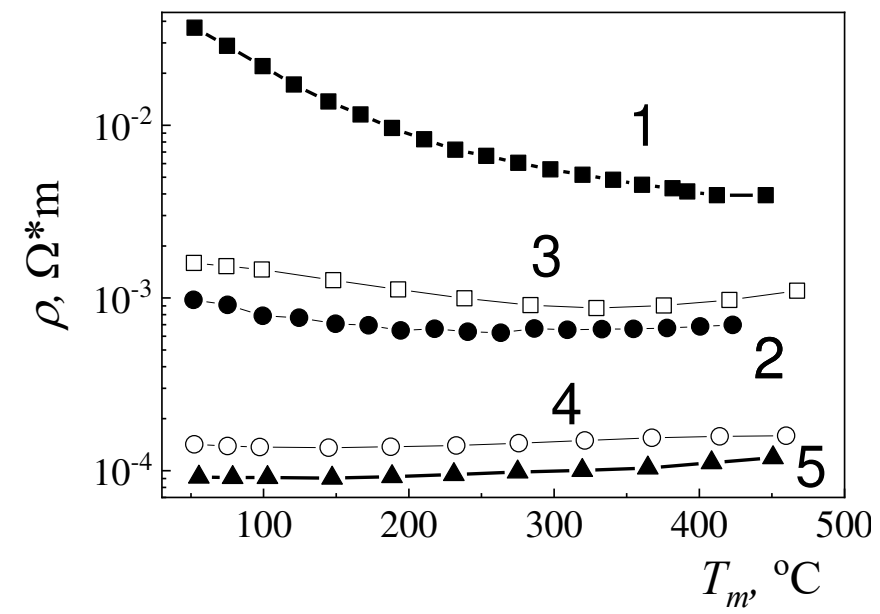

Fig.2. Temperature dependence of resistivity measured for the samples shown in Table 1. The curve number corresponds to the sample number.

The thermal conductivity (Table 2) is approximately the same for all nanostructures, the value lies within the range of $2.5-3.75$ $\mathrm{W} / \mathrm{m} \mathrm{K}$. The latter fact can evidence on the similarity of the presented samples both in composition and in grain size. The values of $\varkappa$ in Table. 2 are close to the ones obtained for $n$ -
$\mathrm{Si}_{0.60} \mathrm{Ge}_{0.40}$, highly doped with As or P [1]. The Seebeck coefficient varies nonmonotonically with varying structural parameters (Table 2), which is believed to be due the $\alpha$ being related with the resistivity. The latter depends not only on the concentration, but also on the homogeneity of the phase composition of the sample.

Table.2. Thermoelectric parameters of $\mathrm{Si}_{0.65} \mathrm{Ge}_{0.35} \mathrm{Sb}_{\delta}$ samples. The parameter were measured at $T_{\mathrm{m}}=450^{\circ} \mathrm{C}$.

\begin{tabular}{|c|c|c|c|c|}
\hline Sample & $\begin{array}{c}\boldsymbol{\rho x 1 0} \mathbf{4}^{\mathbf{4}}, \\
\mathbf{\Omega}^{*} \mathbf{m}\end{array}$ & $\begin{array}{c}\boldsymbol{\alpha}, \\
\boldsymbol{\mu} \mathbf{V} / \mathbf{K}\end{array}$ & $\begin{array}{c}\boldsymbol{x}, \\
\mathbf{W} / \mathbf{m}^{*} \mathbf{K}\end{array}$ & $\mathbf{Z T}$ \\
\hline $\mathbf{1}$ & $40 \pm 2$ & $410 \pm 40$ & $2.5 \pm 0.3$ & $0.03 \pm 0.006$ \\
\hline $\mathbf{2}$ & $7 \pm 0.5$ & $690 \pm 40$ & $3.5 \pm 0.3$ & $0.14 \pm 0.03$ \\
\hline $\mathbf{3}$ & $11 \pm 1$ & $644 \pm 40$ & $3.2 \pm 0.3$ & $0.09 \pm 0.02$ \\
\hline $\mathbf{4}$ & $2.0 \pm 0.2$ & $490 \pm 40$ & $3.75 \pm 0.3$ & $0.30 \pm 0.06$ \\
\hline $\mathbf{5}$ & $1.2 \pm 0.1$ & $490 \pm 40$ & $2.73 \pm 0.3$ & $0.54 \pm 0.1$ \\
\hline
\end{tabular}

Figure 3 shows the temperature dependences of $Z T$, calculated by (1). With the increase of measurement temperature $\mathrm{ZT}$ value monotonically increases and the highest values are characteristic of nanostructures with a $\mathrm{Sb}$ content of 0.7 to 0.9 at. $\%$. A decrease in impurity concentration, as well as a decrease in sintering temperature, leads to a significant decrease in ZT.

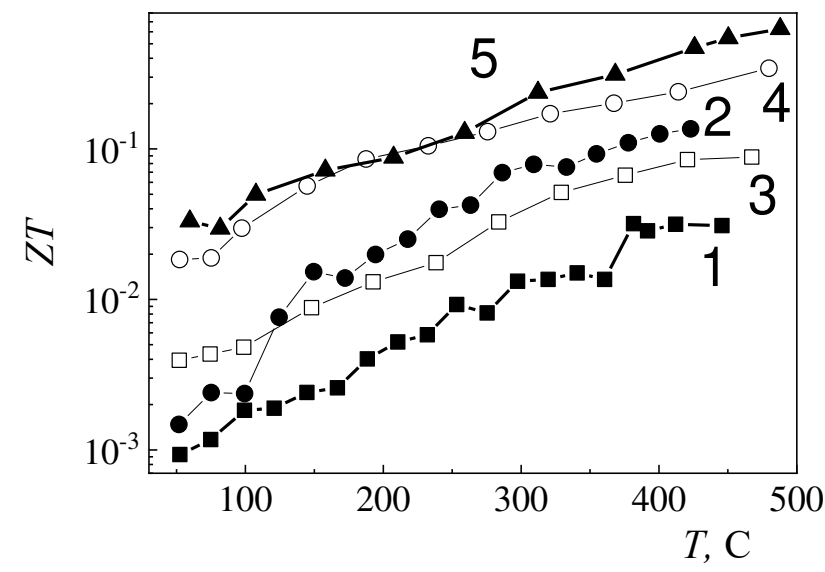

Fig.3. Temperature dependences of the thermoelectric $Z T$ measured for the samples shown in Table 1. The curve number corresponds to the sample number.

The obtained results can be explained in terms of the phase composition of the samples and the degree of the impurity incorporation into the 
substitution position of Ge or Si. An insufficient formation temperature leads to ineffective mixing of $\mathrm{Ge}$ and $\mathrm{Si}$, which is accompanied by the conservation of the silicon phase (this can be seen from the XRD patterns in Fig.1). The resulting heterogeneity of the $\mathrm{Si}_{1-x} \mathrm{Ge}_{x}$ composition leads to a modulation of the band gap, thereby causing a slight increase in resistance (compare samples 3 and 4 in Table 2 with the same $\mathrm{Sb}$ concentration, but different sintering temperatures). In turn the resistance increase causes a decrease in $Z T$.

In addition, the incorporation of substitutional impurities into the solid solution substantially depends on the sintering temperature. We believe that the high resistance values of the low-temperature sample 1 are due to the action of both of the above factors. When sintering the sample with the highest $\mathrm{Sb}$ concentration of 0.9 at.\% and at a higher temperature, the material with the highest value of $Z T$ is formed (sample 5, Table 2).

Finally, we should note that the conditions for efficient phase mixing and conditions for efficient $\mathrm{Sb}$ incorporation may differ. Indeed, one would need fundamentally nonequilibrium sintering conditions to incorporate $\mathrm{Sb}$ impurity over the solubility level whereas $\mathrm{Ge}$ and $\mathrm{Si}$ mixing may occur in the thermal equilibrium.

In particular introduction of $\mathrm{Sb}$ with the concentration of over 1 at.\% in [7] had led to a formation of antimony clusters in the $\mathrm{Si}_{0.65} \mathrm{Ge}_{0.35}$ matrix accompanied with the sharp increase of the resistivity. The poor Ge and $\mathrm{Si}$ intermixing also leads to resistivity increase as has been shown in the present paper (Sample 1).

The experimental conditions described in section 1 allowed us to achieve both sufficient $\mathrm{Ge}$ and $\mathrm{Si}$ mixing and $\mathrm{Sb}$ impurity incorporation sufficient to obtain the high values of $Z T$. We believe that this combination can still be optimized by further manipulation of the parameters of sintering.

\section{Conclusion}

Thus, the study of thermoelectric properties of $\mathrm{Si}_{0.65} \mathrm{Ge}_{0.35}$ with the $\mathrm{Sb}$ impurity has shown that the values of resistivity and thermal conductivity for given impurity concentration are determined mainly by the phase composition of $\mathrm{Si}_{0.65} \mathrm{Ge}_{0.35}$ and the degree of impurity incorporation. The best thermoelectric characteristics were obtained for the structures fabricated at temperatures above $1100{ }^{\circ} \mathrm{C}$. The latter value is close to the melting temperature of $\mathrm{Si}_{0.65} \mathrm{Ge}_{0.35}$ solid solution. The top value of $Z T=0.628$ was obtained at the maximal measurement temperature of $490{ }^{\circ} \mathrm{C}$ for $\mathrm{Si}_{0.65} \mathrm{Ge}_{0.35}$ with 0.9 at.\% of $\mathrm{Sb}$ impurity. This value is comparable with the best known phosphorous doped $\mathrm{Si}_{0.8} \mathrm{Ge}_{0.2}$ analogues $[2,6,9]$. In conclusion, it was demonstrated for the first time that antimony doping, similarly to phosphorus doping, can be used to obtain the $n$-type $\mathrm{Si}_{1-\mathrm{x}} \mathrm{Ge}_{\mathrm{x}}$ thermoelectric solid solutions.

\section{Acknowledgements:}

The work was supported by Russian Science Foundation, project no. 17-79-20173.

\section{References}

[1] Yu B, Zebarjadi M, Wang $H$, et.al. Enhancement of thermoelectric properties by modulation-doping in silicon germanium alloy nanocomposites. Nano Lett. 2012, 12: $2077-$ 2082. https://doi.org/10.1021/nl3003045

[2] Bathula S, Gahtori B, Jayasimhadri M, et.al. Microstructure and mechanical properties of thermoelectric nanostructured n-type silicongermanium alloys synthesized employing spark plasma sintering. Appl.Phys.Lett. 2014, 10: 061902. http://dx.doi.org/10.1063/1.4892879

[3] Chen Z-G, Han G, Yang L, et.al. Nanostructured thermoelectric materials: Current research and future challenge. Prog. Nat. Sci.: Materials International. 2012, 22: 535-549.

https://doi.org/10.1016/j.pnsc.2012.11.011

[4] Shikari Y, Usami N, Silicon-Germanium (SiGe) nanostructures. Production, properties and application in electronics. Woodhead publishing limited. 2011. https://doi.org/10.1016/B978-1-84569-6894.50025-0

[5] Gayner C, Kar KK. Recent advances in thermoelectric materials. Progress Mater. Sci. 

Physics of the Solid State. 2015, 57: 605-612. https://doi.org/10.1134/S1063783415030208

[7] Dorokhin MV, Demina PB, Erofeeva IV, et.al. In-situ doping of thermoelectric materials based on $\mathrm{SiGe}$ solid solutions during their synthesis by the spark plasma sintering technique. Semiconductors. 2019, 53, 11581163.

https://doi.org/10.1134/S1063782619090045

[8] Olesinski RW, Abbaschian GJ. The Sb-Si (Antimony-Silicon) system. Bulletin of Alloy Phase Diagrams 1985, 6: 445-448. https://doi.org/10.1007/BF02869508

[9] Murugasami R, Vivekanandhan P, Kumaran $S$, et.al. Simultaneous enhancement in thermoelectric performance and mechanical stability of p-type SiGe alloy doped with Boron

prepared by mechanical alloying and spark plasma sintering J. Alloys and Comp. 2019, 773: 752-761.

https://doi.org/10.1016/j.jallcom.2018.09.029 [10] Chuvil'deev VN, Boldin MS, Dyatlova YG, et.al. Comparative study of hot pressing and high-speed electropulse plasma sintering of $\mathrm{Al} 2 \mathrm{O} 3 / \mathrm{ZrO} 2 / \mathrm{Ti}(\mathrm{C}, \mathrm{N})$ powders. Russian Journal of Inorganic Chemistry. 2018, 60: 987-993.

[11] Erofeeva IV, Dorokhin MV, Zdoroveyshchev AV, et.al. Production of Siand $\mathrm{Ge}$-based thermoelectric materials by spark plasma sintering. Semiconductors. 2018, 52: 1559-1563.

https://doi.org/10.1134/S1063782618120072 [12] Devyatkova ED, Petrov AV, Smirnov IA, Moizhes BY. Fused silica as a reference material in measurements of thermal conductivity. Soviet Phys.-Solid State 1960, 2, 738-746.

Slack GA. Platinum as a Thermal Conductivity Standard. J.Appl.Phys. 1964, 35: 339-344. https://doi.org/10.1063/1.1713313 
Figures

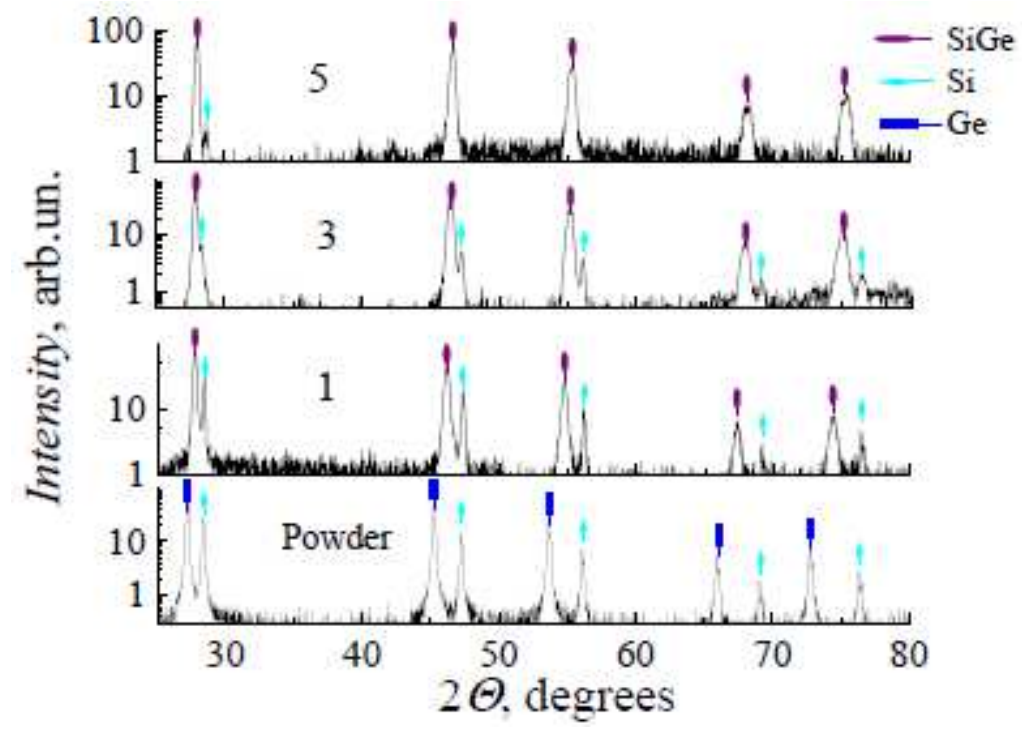

Figure 1

X-ray diffraction pattern for samples 1,3 , and 5 , as well as for the initial powder (Powder). The icons indicate the positions of the peaks for $\mathrm{Si}, \mathrm{Ge}$, and a GeSi solid solution.

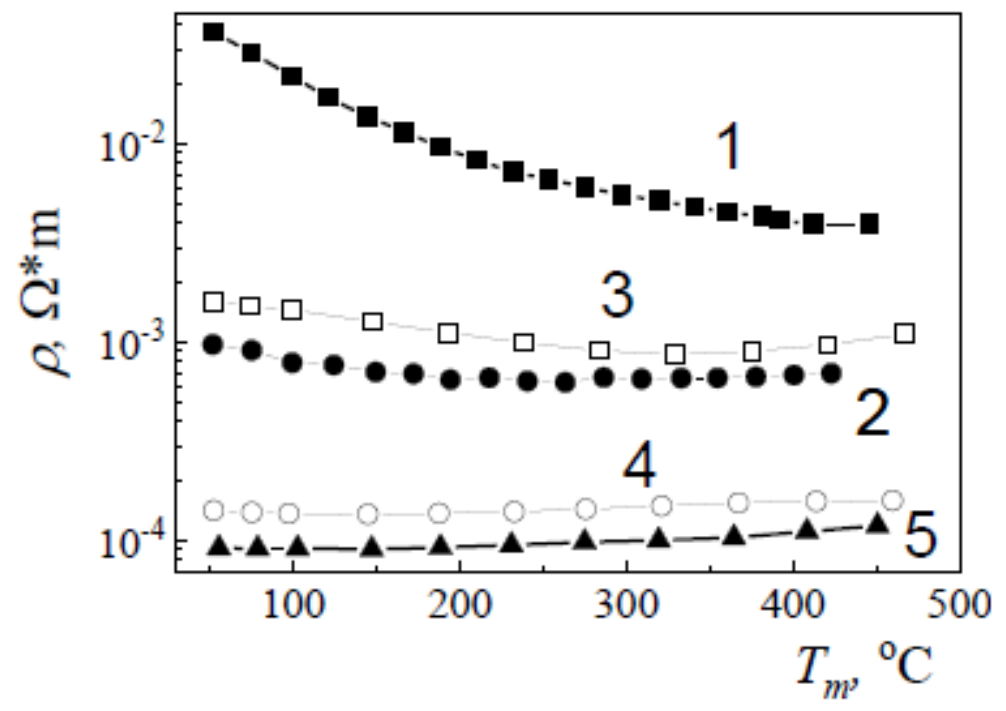

Figure 2

Temperature dependence of resistivity measured for the samples shown in Table 1 . The curve number corresponds to the sample number. 


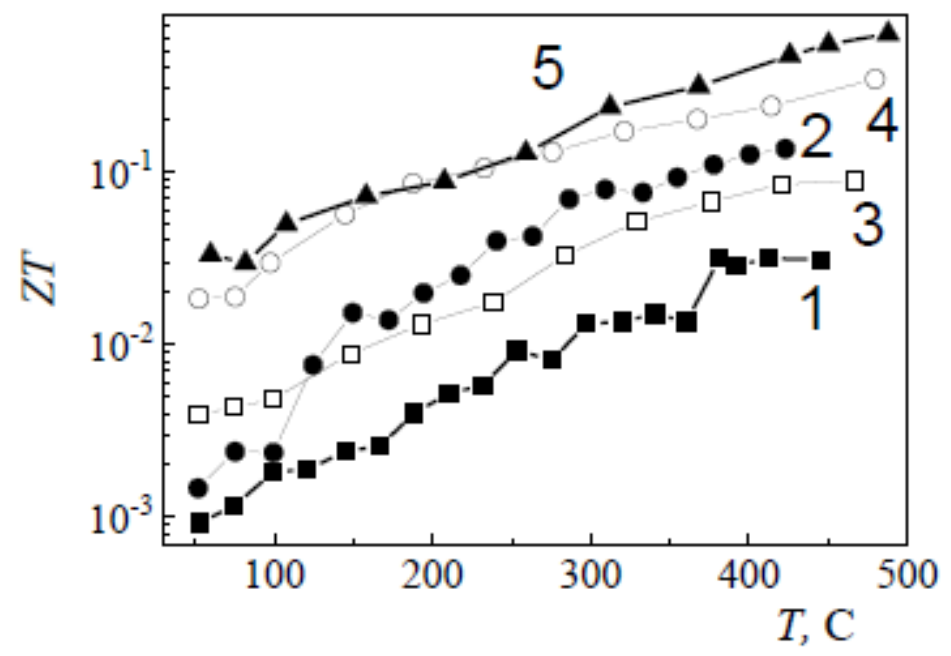

Figure 3

Temperature dependences of the thermoelectric ZT measured for the samples shown in Table 1. The curve number corresponds to the sample number. 